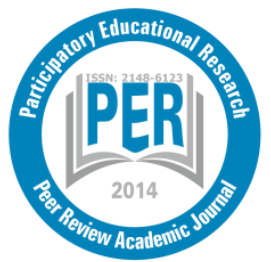

Participatory Educational Research (PER)

Vol. 3(2), pp. 1-13, August, 2016

Available online at http://www.partedres.com

ISSN: $2148-6123$

http://dx.doi.org/10.17275/per.16.06.3.2

\title{
Motivation, Learning, and Technology: Applying the ARCS-V Motivation Model
}

\begin{tabular}{|c|c|}
\hline & $\begin{array}{l}\text { John M. Keller } \\
\text { Florida State University, USA }\end{array}$ \\
\hline Article history & The ARCS-V model (an acronym for attention, relevance, confidence, \\
\hline $\begin{array}{l}\text { Received: } \\
15.04 .2016\end{array}$ & $\begin{array}{l}\text { satisfaction, and volition) contains a synthesis of motivational and } \\
\text { volitional concepts and theories that provide a foundation for a }\end{array}$ \\
\hline $\begin{array}{l}\text { Received in revised form: } \\
20.04 .2016\end{array}$ & $\begin{array}{l}\text { motivational design process that has been validated in many contexts } \\
\text { (Keller 2010). This paper begins with a listing of many of the technology } \\
\text { applications and delivery system options that are now available to }\end{array}$ \\
\hline $\begin{array}{l}\text { Accepted: } \\
21.04 .2016\end{array}$ & $\begin{array}{l}\text { instructional designers and teachers, but then goes on to describe learner } \\
\text { motivation challenges that still occur despite these innovations. Part } 2 \text {, the }\end{array}$ \\
\hline Key words: & major part of the paper, describes the ARCS-V motivational synthesis \\
\hline $\begin{array}{l}\text { Motivation, Learning, } \\
\text { Technology, ARCS-V }\end{array}$ & $\begin{array}{l}\text { and how to apply it to identify motivational characteristics and problems } \\
\text { of learners together with a systematic process for designing and } \\
\text { implementing motivational solutions. This design approach includes a 10- } \\
\text { step process as well as a simplified version of the process to aid in lesson } \\
\text { and module planning. It also includes a self-reflective checklist that an } \\
\text { instructor can use to identify which aspects of motivation are satisfactory } \\
\text { and which require strengthening. The final part of the paper provides } \\
\text { examples of motivational strategies and a case description of the } \\
\text { motivational enhancement of an instructional module in three different } \\
\text { delivery contexts: classroom instruction, blended learning, and eLearning. }\end{array}$ \\
\hline
\end{tabular}

\section{Introduction}

Technology infusions into learning environments have grown exponentially during the past two decades and with the accelerating rate of inventions and innovative applications can be expected to continue to do so. Each new technology application is accompanied by a predictable wave of publications describing its benefits and applications. However, the novelty effect associated with each of these innovations soon fades leaving researchers with the continuing problems of providing learning experiences that are motivating to the learners and instructionally effective. Certainly, adaptations of basic knowledge of motivation and learning have to be made in accordance with the specific characteristics of a given technology or delivery system, but there are fundamental principles of motivation and learning that transcend these differences. The focus in this paper is on motivation to learn and it begins with a discussion of issues and problems related to technology and motivation. The second major part of the paper describes a generalized process for identifying motivational characteristics and problems of learners together with a systematic process for designing and implementing motivational solutions. This process, which can be applied with any delivery system, has been used in many different settings internationally and at any grade level (Keller

*Correspondence: Professor Emeritus, 9705 Waters Meet Drive Tallahassee, Florida 32312, USA

jkellersan@gmail.com 
2010). The final part of the paper describes tools and examples including the development of a strategy portfolio with examples of three generalizable strategies. It also includes a case example of conducting and applying the results of a motivational analysis to a module within a graduate course in instructional design. The example includes the results of the analysis and resulting revisions to both blended learning version of the module and an adaptation to an elearning version of it.

\section{Part 1. Technology and Motivation}

\section{Technologies and technology-assisted learning environments}

This is an exciting time for instructional designers and instructors because of the broad variety of technology applications that are available to assist in creating interesting lessons and activities. These affordances, or resource opportunities, include such things as productivity software, help systems, data bases, expert systems, wireless communications, email, Facebook, Skype, LinkedIn, smart phones, YouTube, and QR codes to mention only a few. Furthermore, there is a tremendous variety of learning environments and pedagogical strategies (Table 1). One of the striking things about modern learning environments is that they can occur almost anywhere and at any time thanks to the vast number of delivery system options.

Table 1. Examples of learning environments and pedagogical strategies

\begin{tabular}{ll}
\hline - distance learning & - flipped classroom \\
- e-learning & - distributed learning \\
- mobile $(M-)$ learning & - blended learning \\
- massive open online courses (MOOCs) & - hybrid learning \\
- Virtual worlds & - online learning \\
- Second-Life & - and even "traditional" classroom \\
- OpenSim & learning, which usually means \\
- Minecraft & nothing more than attending lectures \\
\hline
\end{tabular}

Many educators get very excited about the possibilities offered by these e-learning and technology innovations, but many others do not. Similarly, students are sometimes excited by new techniques and technologies, but their interested is frequently short-lived. Just as students are not always motivated to learn, teachers are not always motivated to teach. Of course, this is not a new insight but what are some of the reasons?

\section{Motivational Obstacles and Problems}

The job of teaching, like the requirement of being a high performing student, contains many obstacles to building and sustaining personal motivation. For example, some of the questions asked by teachers are:

- How can I motivate kids when I don't have any money for prizes and other rewards?

- Can I have a real and meaningful influence on learner motivation?

- What are the critical things to know about learner motivation?

- How can I determine if I have a discipline problem or a motivation problem?

- How can I find time to deal with motivation when my teaching requirements are so heavy? 
- What can I do when my own motivation is low?

- What are some specific tactics that I can use to motivate students?

- How do I decide which motivational tactics to use - intuition, personal appeal?

- How can I make my class interesting and fun and still keep my high academic standards?

- What do I do if I don't have a "magnetic" personality that appeals to kids?

Students also have their lists of motivational challenges. A few examples are:

- How can I be motivated when the instruction seems to be useless?

- How can I stay awake and learn when the instruction is boring?

- Why can't I take classes that I want to take?

- How do I overcome my fears when I am not confident about learning a given topic or task?

- What do I do when I have emotional problems in my life that interfere with learning

There are also many challenges with regard to implementation problems and social support, especially in e-learning and even more so in self-directed settings where students are not actively engaged with instructors and other students. Implementation problems can result from such things as poorly designed materials that lack well-written text with adequate examples and exercises and from confusion due to organizational and navigational problems. Marcus Deimann (Deimann and Keller 2006) called two of these problems "lost in hyperspace" and the "serendipity effect." It can be easy to get "lost" when the navigational support in a program is not clearly defined and is easy to defeat by clicking on icons that branch away without clearly marked return paths. It can also become too easy to get distracted when one link in a program leads you serendipitously to other links that branch away into areas of personal interest that digress from the lesson.

Social support problems can occur when learners are not part of a social network and have no opportunity for collaboration, and when motivational support is not available when and where it is needed. Depending on their learning styles, some students might prefer to be independent and learn on their own, but a complete lack of social support is usually detrimental.

The question is, given all these challenges, how can you systematically stimulate and sustain learner motivation? Is it even possible? The thesis in this paper is that, "Yes, it is possible." To illustrate this, the next section of this paper will describe a motivational theory of learning and a motivational design process that have been validated in many different settings and with many types of learners. The third part of the paper will provide a variety of examples of applying the process.

\section{Part 2. Motivational Challenges and Design Process}

\section{Conceptual Foundation}

Concerns about human motivation and how to influence it have been expressed throughout history. Aristotle, for example, asked, "Why is man born to wonder" (Wheelwright 1951)? In the contemporary world a dominant explanation of how to motivate people was provided by behavioral psychology. From a highly simplified perspective, it states that you can motivate people with a "carrot or stick;" that is, you can motivate them to move toward a goal or acquire a new behavior by rewarding positive behaviors related to the desired behavior ("carrots"). In contrast, you can motivate them to avoid given behaviors, or 
to stop doing them, by punishing instances of those behaviors by ignoring them or administering painful consequences (the "stick").

However, this approach omitted consideration of the many cognitive and emotional aspects of a person that influence behavior. A more comprehensive definition of motivation is that it refers to those things that explain the direction, magnitude, and persistence of behaviors (Keller 1983) and there are many, many theories and concepts that have been formulated to explain aspects of motivation. However, this diversity did not provide a useful foundation for understanding and influencing motivation in a learning environment. There were too many concepts and theories to be useful for design and many of them had overlapping elements. Because of this, Keller, together with the help of several graduate students, created a synthesis of motivational concepts that provided a foundation for the development of a systematic motivational design process. This effort resulted in a syntheses with four categories of motivational variables that were first called "interest," "relevance," "expectancy," and "outcomes" (Keller 1979). Continuing work with this theoretical model shifted toward an application-focused model and this led to a renaming of some of the categories in order to produce an acronym that would be more memorable while still being theoretically valid. The new structure (Keller 1984) was now called the ARCS model (attention, relevance, confidence, and satisfaction).

The attention category incorporates research on curiosity and arousal, interest, boredom, and other related areas such as sensation seeking.

The second category, relevance, refers to learners' perceptions that the instructional requirements are consistent with their goals, compatible with their learning styles, and connected to their past experiences.

The third category, confidence, refers to the effects of positive expectancies for success, experiences of success, and attributions of successes to one's own abilities and efforts rather than to luck or to task challenge levels that are too easy or difficult.

The fourth condition of motivation is required is called satisfaction. It includes the appropriate mix of intrinsically and extrinsically rewarding outcomes that sustain desirable learning behaviors and discourage undesirable ones.

These four categories provided a basis for aggregating the various concepts, theories, strategies, and tactics that pertain to the motivation to learn (Keller 1987a), but over time it was shown that they did not adequately account for differences in persistence among learners. Those who were highly motivated would persist until they accomplished their goal, but those who were not so strongly motivated would procrastinate or give up even when the final goal was important to them. To explain differences among these learners and provide a basis for motivational support activities, a fifth category was added (Keller 2008). It was called volition,(Kuhl 1987) which was similar to self-regulation (Zimmerman 2001), and it incorporated variables and strategies related to persistence.

\section{From Concepts to Strategies}

These five categories provided a basis for transitioning into a more applied model. Sets of strategy prescriptions were developed for each of the five categories. Complete descriptions and examples appear in numerous publications (see Keller 2010) but in brief they are as follows: 
To generate and sustain attention, use tactics that capture interest, stimulate inquiry, and maintain attention. To make instruction relevant to the learners, relate it to their goals, match it to their interests, and tie it to their experiences. Build or sustain confidence by creating success expectations, providing opportunities for success, and instilling personal responsibility for success. Satisfaction with the learning experience can be achieved by reinforcing an intrinsic sense of satisfaction, providing extrinsically rewarding outcomes, and treating learners fairly. Finally, support learner persistence by helping them learn to state their goal intentions in concrete terms, take actions that support their efforts, and regulate their behaviors to stay on task.

These concepts, theories, strategies, and tactics comprise the first major part of the ARCS-V model, which is the synthesis of the vast motivational literature into a simple and useful number of components. They also provide the basis for the second major feature of the ARCS-V model which is the systematic design process (Keller 1987; Keller 2010) that assists you in creating motivational tactics that match student characteristics and needs.

\section{Motivational Design Process}

The ARCS model contains a ten-step design process for the development of motivational systems in work and learning settings (Table 2). The first two steps, which are parts of the overall analysis components of the process, produce information about the status quo and provide the basis for analyzing gaps and their causes which are done in the third and fourth steps. Based on these analyses, Step 5 involves the preparation of motivational objectives and specifications for how they will be assessed. There are then two steps in design. Step 6 consists of brainstorming within each motivational category to generate a rich list of potential solutions. Step 7 is more critical and analytical for the purpose of selecting solutions that best fit the time, resource, and other constraining factors in the situation. The final three steps include both development and evaluation, and are similar to any other development model.

Table 2. ARCS-V systematic motivational design steps

\begin{tabular}{ll}
\hline 1. Obtain course information & 6. List potential tactics \\
2. Obtain audience information & 7. Select \& design tactics \\
3. Analyze audience & 8. Integrate with instruction \\
4. Analyze other course elements & 9. Select and develop materials \\
5. List objectives and assessments & 10. Evaluate and revise \\
\hline
\end{tabular}

These 10 steps follow a typical problem-solving and design process, but three steps that are particularly important are (3) audience analysis, (6) list potential tactics, and (7) select \& design tactics. Analyzing the audience's motivation to learn a particular topic is different from most other analysis models because it is curvilinear. This means that it can be too low but it can also be too high as illustrated in Figure 1. 


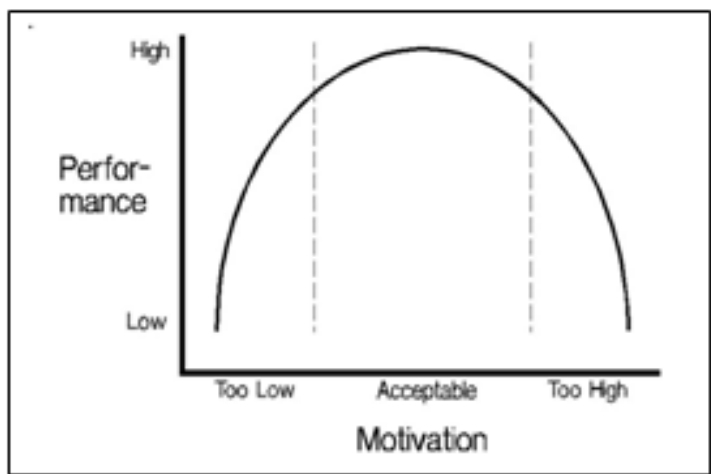

Figure 1. Inverted U-curve for motivational analysis

When analyzing an audience, whether an individual or group, each of the five components of the ARCS-V model must be considered in order to predict whether motivation will be too low, satisfactory, or too high. For example:

Attention Readiness: Refers to the degree to which the audience will be likely to respond with curiosity and attention to the instructional material. At one extreme, the audience can be under stimulated (bored) and not likely to pay attention or, at the other extreme, overstimulated (hyper) and unable to keep their attention on any one stimulus.

Perceived Relevance: Refers to whether the audience is likely to perceive any personal benefit from the course with respect to motive or goal attainment. At one extreme the audience will be indifferent or even hostile if they perceive no relevance. At the other extreme, perceived relevance may be so high due to the importance of this course to their future goal attainment (e.g. graduation, promotion, job retention, scholarship) that they have high anxiety due to feelings of jeopardy.

Felt Confidence: Refers to how likely the audience is to feel a comfortable sense of challenge in the course. If they feel too unconfident, they will experience feelings of helplessness ("I can't do this no matter how hard I try"). If they are overconfident they will be cocky and believe they already know the concept or skill that is being taught. This will cause them to perceive only the things that they do, in fact, know and overlook the gap between what they actually know and what the course is teaching.

Satisfaction Potential: Refers to the audience's preconceived ideas about how they will feel about the outcomes of the course. At one extreme, the reluctant learners may have a feeling of "sour grapes" ("No matter how well I succeed in this course, I'm still not going to like it"). At the other extreme, they may be expecting too much from the course, a feeling of panacea as if the course were going to solve all their problems or help them achieve total mastery of the given skill.

Volitional Strength: Refers to the degree of commitment the students have toward achieving the learning requirements and whether they will persist to the end. If volition is weak, they will be easily distracted and not likely to develop good study plans. If it is too high, they will have difficulty knowing how and when to reach closure on their studies; they will over study in an anxious manner instead of a way that increases learning and retention.

The results of this analysis will determine whether it will be necessary to remedy a motivational problem by using strategies aimed at increasing or decreasing motivation in the 
problem areas or simply to maintain an already satisfactory level of motivation. This is important because the use of unnecessary or excessive motivational strategies will take away from valuable instructional time and annoy the students if they are already highly motivated to learn the material.

Steps 6 and 7 are also critical parts of the motivational design process. When doing instructional design, the instructional analysis usually results in specifications as to the concepts or skills to be taught and the methods (rules, examples, and practice activities) for teaching them. But, when doing motivational design the process is not so prescriptive. For example, if the motivational challenge is how to increase the perception of relevance among a group of students there are no prescriptions as to how to do this. Instead, in Step 6, a set of possibilities is prepared based on things they have done in the past, activities they have observed in other situations that can be modified and transferred to the present situation, reviews of books containing generic games and group activities, and other sources of learning activities. After preparing the list of potential activities the process of selection and design is done in Step 7. Selection decisions are based on design requirements including time, cost, and appeal. Sometimes a time-consuming strategy can be simplified and adapted to a given situation.

\section{A Simplified Approach}

The 10-step model has been applied in all types of learning environments such as classroom instruction, self-paced print, computer-based instruction, and multimedia, but it was sometimes difficult to use this full-featured process because it was time consuming. Parts of the process, such as Steps 1 and 2, were not needed in settings where, for example, teachers were already highly familiar with their setting and the backgrounds of their students which means that their focus was on creating lessons or modules, not entire courses. A solution to this problem was provided by Professor Katsuaki Suzuki while serving as a consultant for a computers-in-education project at a junior high demonstration school in northern Japan. He reduced the process to analysis and design and developed a single matrix (Suzuki and Keller 1996) in which the results of these decisions can be portrayed. In the first row, the designer lists salient characteristics of the learners' overall motivation to learn. The second row contains the designer's judgments about how appealing the learning task will be to the learners. The third and fourth rows ask about learners' expected attitudes toward the medium of instruction and the instructional materials. Each of the entries in these rows has a "plus" or "minus" sign to indicate whether it is a positive or negative motivational characteristic. Based on the information in these first three rows, the motivational designer decides how much motivational support is required and what types of tactics to use, and then lists tactic ideas in the bottom row.

An illustration of this approach is shown in Table 3 which contains a summary of applying it to "Introduction to Instructional Systems," an introductory course at the graduate level at Florida State University. This program contained students with many different academic backgrounds and amounts of work experience because there was no "feeder" program that provided undergraduate preparation in this field of study. At the time of this design example, the course was primarily a traditional lecture class with a multi-faceted term project and exams. This analysis illustrated that many parts of the course were satisfactory but there were numerous "pockets," especially regarding confidence, that needed revision. 
Table 3. ARCS simplified design matrix for "Introduction to Instructional Systems"

\begin{tabular}{|c|c|c|c|c|}
\hline \multirow[b]{2}{*}{ 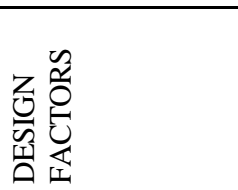 } & \multicolumn{4}{|c|}{ ARCS CATEGORIES } \\
\hline & Attention & Relevance & Confidence & Satisfaction \\
\hline 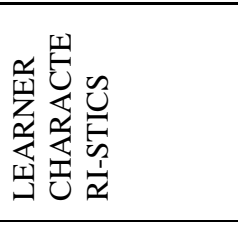 & $\begin{array}{l}\text { Required core } \\
\text { course at } \\
\text { graduate level; } \\
\text { high interest (+) }\end{array}$ & High commitment (+) & $\begin{array}{l}\text { New to graduate } \\
\text { program; not sure } \\
\text { what to expect (-) }\end{array}$ & $\begin{array}{l}\text { They expect to be } \\
\text { pleased about their } \\
\text { newly chosen } \\
\text { program }(+), \\
\text { but not certain } \\
(-)\end{array}$ \\
\hline 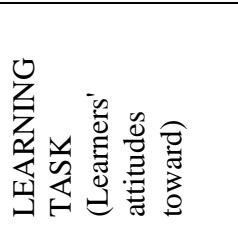 & $\begin{array}{l}\text { Not sure what to } \\
\text { expect but eager } \\
\text { to find out }(+)\end{array}$ & $\begin{array}{l}\text { Term project is } \\
\text { extremely time } \\
\text { consuming and } \\
\text { complex (-); } \\
\text { But has applied focus } \\
(+)\end{array}$ & $\begin{array}{l}\text { Seems confusing } \\
(-), \\
\text { First exposure to new } \\
\text { concepts and } \\
\text { professional jargon (-) }\end{array}$ & $\begin{array}{l}\text { High applic-ability of } \\
\text { most of acquired } \\
\text { skills (+), } \\
\text { but not all (-) } \\
\text { Learning a new career } \\
\text { focus (+) }\end{array}$ \\
\hline 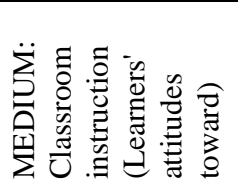 & $\begin{array}{l}\text { Curious to learn } \\
\text { about } \\
\text { instructor's } \\
\text { style \& expecta- } \\
\text { tions. (+) }\end{array}$ & $\begin{array}{l}\text { A familiar means of } \\
\text { instruction. }(+)\end{array}$ & $\begin{array}{l}\text { Worried about } \\
\text { workload and } \\
\text { difficulty level. (-), } \\
\text { but expect to succeed. } \\
(+)\end{array}$ & $\begin{array}{l}\text { Will feel happy if } \\
\text { successful. (+) }\end{array}$ \\
\hline 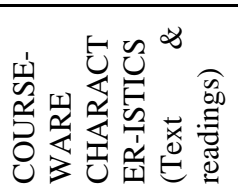 & $\begin{array}{l}\text { Technically } \\
\text { accurate but } \\
\text { 'dry'. (-) }\end{array}$ & $\begin{array}{l}\text { Content is highly } \\
\text { relevant to career } \\
\text { needs. }(+)\end{array}$ & $\begin{array}{l}\text { Abstract and } \\
\text { theoretical. (-) }\end{array}$ & $\begin{array}{l}\text { Will lead to career } \\
\text { relevant skills. }(+)\end{array}$ \\
\hline 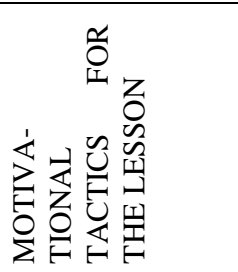 & $\begin{array}{l}\text { Minimal tactics } \\
\text { required. } \\
\text { Use anecdotes } \\
\text { and open-ended } \\
\text { problems to } \\
\text { introduce lesson } \\
\text { content. }\end{array}$ & $\begin{array}{l}\text { Minimal tactics } \\
\text { required. } \\
\text { Use workplace } \\
\text { relevant examples and } \\
\text { case studies. }\end{array}$ & $\begin{array}{l}\text { Necessary to build } \\
\text { confidence. } \\
\text { Set objectives } \\
\text { cumulatively from } \\
\text { low to high. } \\
\text { Use teams with case } \\
\text { studies. }\end{array}$ & $\begin{array}{l}\text { Minimal tactics } \\
\text { required. } \\
\text { Provide timely } \\
\text { feedback illustrated } \\
\text { with example from } \\
\text { the working } \\
\text { environment. }\end{array}$ \\
\hline
\end{tabular}

This simplified process can be modified for different situations. For example, Lya Visser (1998) adapted the matrix to apply to her research on motivational messages within a semester-long distance learning course (see Keller (2010) for a brief summary). She had four analysis rows, a summary row, and a results (tactic suggestions) row. The four analysis rows were:

1. Precourse attitudes of students toward distance learning

2. Midterm attitudes toward distance learning

3. Student reactions to this course content

4. Characteristics of student support during the course.

One more example of an analysis tool is a simple reflective checklist that can be used by teachers to examine and improve their own motivation as well as the motivation of their students. Enthusiasm is one of the characteristics of highly effective teachers; however, it is difficult if not impossible for most human beings to always feel enthusiastic about everything they do. Also, teachers usually have some topics they enjoy teaching and others that do not greatly interest them. And, when a teacher is not interested in the topic it can be very difficult to inspire students to learn that content. Thus, to assist teachers in examining their own motivation and their readiness to incorporate tactics that will motivate the students, the author prepared a job aid that guides teachers in reflecting about each component of the ARCS-V model. This job aid (Table 4) can be used in the lesson planning phase to assist in making 
notes about motivational attitudes and ideas. It can also be used during the process of teaching the course when motivational problems seem to be occurring.

Table 4. Job aid for motivational strategy design

\begin{tabular}{|l|l|l|}
\hline Categories & Instructor's Self-Analysis & Instructor's Analysis of Learners \\
\hline Attention & $\begin{array}{l}\text { Am I excited about this learning } \\
\text { experience and how I can make it } \\
\text { interesting? }\end{array}$ & $\begin{array}{l}\text { Are the learners going to be interested? What } \\
\text { tactics will stimulate their curiosity and interest? }\end{array}$ \\
\hline Relevance & $\begin{array}{l}\text { Do I believe that this learning experience } \\
\text { will be valuable for my learners? }\end{array}$ & $\begin{array}{l}\text { Will learners believe it is valuable? What can I do } \\
\text { to help them believe it is important? }\end{array}$ \\
\hline Confidence & $\begin{array}{l}\text { Am I confident in my ability to lead this } \\
\text { learning experience effectively and } \\
\text { interestingly? }\end{array}$ & $\begin{array}{l}\text { Will the learners feel confident about their ability } \\
\text { to learn this? What do I need to do to help them } \\
\text { be confident? }\end{array}$ \\
\hline Satisfaction & $\begin{array}{l}\text { Do I expect to have positive feelings } \\
\text { about this learning experience? }\end{array}$ & $\begin{array}{l}\text { What can I do to help the learners feel good about } \\
\text { their experience and desire to continue learning? }\end{array}$ \\
\hline Volition & $\begin{array}{l}\text { Will I provide effective supervision and } \\
\text { support to the learners throughout this } \\
\text { learning event? }\end{array}$ & $\begin{array}{l}\text { What can I do to help the learners maintain their } \\
\text { goal orientation and task-focus throughout this } \\
\text { learning event? }\end{array}$ \\
\hline
\end{tabular}

\section{Part 3. Applying the Model with Instructors, Designers, and Learners}

\section{Motivational Strategy Frameworks, Portfolios, and Tactics}

\section{Create a Strategy Portfolio}

After completing the motivational analysis, the next question is where do you get ideas and "recipes" for teaching and learning strategies that will be interesting and effective? An internet search for "teaching strategies" will yield many sources of ideas and you can build your own library of references and portfolio of methods that seem promising or that have worked for you. Related search topics are "games" and "group learning activities." Also, there are many resources available, especially in the training and adult education literature, which you can draw upon. Three examples of these are "Empowering Online Learning" (Bonk and Zhang 2008), "Adding Some TEC Variety: 100+ activities for motivating and retaining learners online" (Bonk and Khoo 2014), and "The Winning Trainer" (Eitington 2001).

When using these resources you might not find an activity that is precisely what you are looking for, such as "using a game to teach how to write behavioral objectives," but you can probably find game structures that you can adapt to your specific situation. For example, these training method resources will have several examples of group activities which include differentiated tasks and evaluation activities. Using one of these "templates," you could divide your class into small groups of two or three people. You could teach them about behavioral objectives and then have each group write several objectives for a given learning task. Next, you could have the groups exchange their objectives, give them an evaluation checklist which they would use to evaluate and score the ones they receive. During the evaluation part of this activity, students will become aware of different interpretations of the material and have to resolve disagreements before awarding a final score. 
Another approach that worked well for the author in addition to finding printed resources was to observe how people teach, not just what they teach. Anytime you attend a lecture, workshop, or other instructional event, take notes on the way the presenter organizes the material and activities. For example, everyone is familiar with the technique called "progressive disclosure" in which the items in a list are covered with a mask and then revealed one at a time as each is discussed. One time when the author was serving as an evaluator for a new workshop the leader used a creative variation of this technique that was highly successful. At one point when we came back from a break, the leader, who liked to use easels and flipcharts, had five or six of them in the front of the room but they were all facing backward to the audience. Then, when he was ready to address the content on a given flipchart he would turn the easel around to face the audience and each one had interesting illustrations on it. With this tactic, he was able to maintain a high level of curiosity! Now, with presentation software, such as PowerPoint, it is easy to achieve similar results with the computer and projection screen. For example, one of the author's slides is on the topic of how to stimulate and sustain curiosity. But, instead of having a bulleted list of the techniques to reveal one at a time, the slide (Figure 2) contains curiosity arousing imagery within a colorful outdoor scene containing road signs with hidden content, a highway disappearing into the distance, and question marks across the top of the scene. Then, each black rectangle mask disappears when the author is ready to talk about the message on a given road sign.

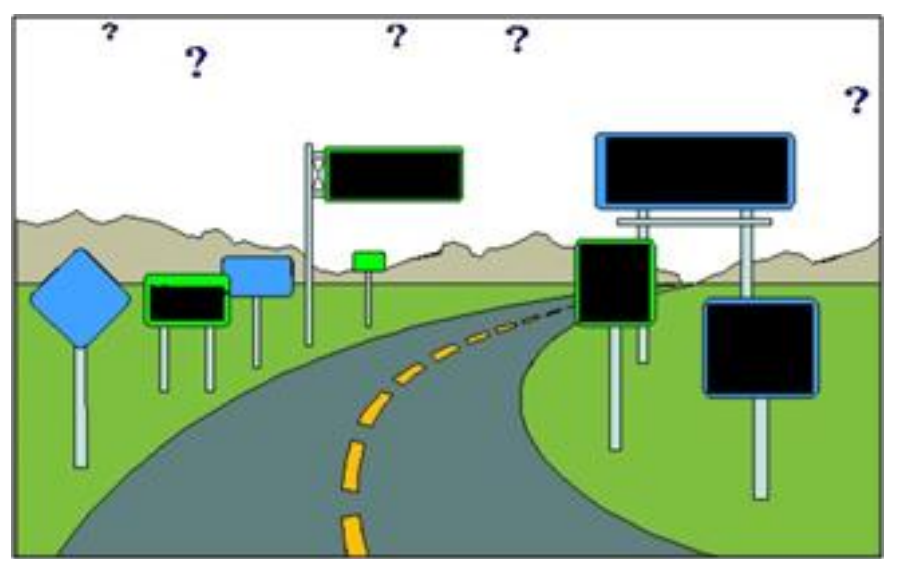

Figure 2. Example of masking for progressive disclosure in a PowerPoint slide

A key point of this topic is that you must not expect to find intact techniques to solve your motivational challenges. It sometimes happens, but for the most part you must actively think about ways to adapt and apply your experiences and strategies that you discover to meet your current requirements. And, it is critical to never forget to include variety and consideration of relevance of your strategies to the learning objectives.

\section{Use an Appropriate Strategy}

Following are three examples of strategies that are particularly relevant to developing motivating learning experiences:

Create a felt gap: In the instructional design literature a first step in the process is to identify the gap between what the learners know and what they are supposed to know. However, even if you do this and design relevant instruction it does not ensure that the learners will believe that they have a "gap." Thus, one of the first steps in motivational design is to create a "felt gap:" that is, to do something that creates an awareness of their gap within the learners. 
People will not engage in learning unless they perceive a gap between what they know and what they want to know or need to know. Examples of how to do this can be found in Keller (2010).

Flip the classroom: This idea has become extremely popular, especially since the publication of "Flip your classroom: Reach every student in every class every day" (Bergmann and Sams 2012). However, this strategy is very old. On the one hand it is nothing more than a strategy in which learners acquire prerequisite knowledge and skills before coming to the classroom and then use the classroom time to participate in "hands on" problem solving or project activities. The popularity of the "flip the classroom" metaphor is based on removing as much of the didactic instruction from the classroom as possible and using classroom time for group learning and other active learning approaches. This has helped legitimize a movement away from traditional lecture as the dominant way in which classrooms are used, but it is far from unprecedented. Many of the instructional strategies described in the Joyce \& Weil (1980) "Models of Teaching" books used what would now be called "flipped" approaches. This was, in fact, the dominant strategy that the author used during most of his graduate teaching career without ever putting a label on it. The author would require students to read the assignments before coming to class and often there would be an assignment to do ahead of time. Then, in class the author would have a short lecture, if any, and discussion to highlight key points and provide supplemental information from his experience. But the majority of class time would be spent on group learning activities that included games, simulations, and problem-based learning activities.

Produce a problem-based learning environment: Problem-based learning strategies have inherent motivational properties and what's more, they mirror in many respects the instructional systems design process. They begin with a problem, usually ill-structured, and require the learner to develop a problem description defined as a gap between the way things are and the way they should be based upon an already defined goal or desired state of affairs. Then, the learners analyze the problem to identify the things that are known about it and the things that need to be known. This is followed by a statement of objectives in behavioral terms and descriptions of measurable results that specify what the desired outcomes are and how it will be known if they have been achieved. The next step is for the learners to generate a list of possible solutions to the problem and select the one that seems to be most effective and cost efficient. At this point, they can either compare their proposed solutions to a "school solution" as is done in case studies or develop and evaluate their solution if time and resources permit.

These three examples illustrate how you can use specific techniques or more comprehensive teaching strategies and models to incorporate into a course. There are, of course, many more examples in the references that have been cited in this article.

\section{Case Example of Motivational Design}

The final part of this paper describes how a fairly traditional graduate course was revised to be more of a problem-based experience which used a "flipped learning" approach. This case example is based on one module from the "Introduction to Instructional Systems" course that was described above in the section titled "A Simplified Approach." 


\section{The situation:}

Graduate course in Instructional System Design. The heterogeneous audience consisted of students who had just finished their undergraduate programs in a variety of majors, students who has actually been working in the field for a period of time but had little or no formal knowledge of this career field, students who were changing career fields, and miscellaneous others. Their expectations were that upon finishing their masters degree they would be able to get a job in this field or continue on for a doctoral degree.

In the present situation they were enrolled in the introductory course which provided a broad understanding of the instructional system design process which stood in contrast to one of the other required introductory courses which focused on the detailed application of the instructional systems design process to the design and evaluation of a specific unit of instruction.

Topic: The topic of the module being addressed in the present case example was Job/Task Analysis. It followed two previous modules which were a general introduction to the field and needs assessment. This topic is also taught in other fields of study such in management, industrial psychology, and industrial engineering.

Goal: The goal was for learners to learn how to design and implement large scale job/task analysis projects in contrast to the micro-level analysis they would do for a specific lesson design project in their other introductory class.

Constraint: This was but one of 10 major topics in the class. Hence, the module objective was limited to planning and conducting a job/task analysis

\section{Status quo before applying motivational design}

When the author inherited the class, the typical structure of weekly class sessions consisted of homework in which students would read the assignment in preparation for class. The class sessions consisted of a lecture-discussion containing key concepts, elaboration of procedures that were described in the textbook, and an occasional learning activity such as critiquing a sample task analysis. The instructor would sometimes solicit examples from the more experienced learners in the class and then conclude the lesson with an application assignment that required the students to prepare a job/task hierarchy from a set of data provided by the instructor.

\section{Motivational Analysis}

After following the established course structure for one semester, the author conducted a motivational analysis in preparation for revising the class. There were problems in every category except volition (Table 5).

Table 5. Results of motivational analysis in case example

\begin{tabular}{|l|l|}
\hline Attention: & $\begin{array}{l}\text { A1 Low side of okay; mind sometimes wanders } \\
\mathrm{A}_{2} \text { Curiosity not stimulated }\end{array}$ \\
\hline Relevance: & $\begin{array}{l}\mathrm{R}_{1} \text { Topic is relevant to career preparation } \\
\mathrm{R}_{2} \text { Lesson content only partially relevant }\end{array}$ \\
\hline Confidence: & $\begin{array}{l}\mathrm{C}_{1} \text { Getting a good grade } \\
\mathrm{C}_{2} \text { Not being able to do it in practice }\end{array}$ \\
\hline Satisfaction: & Somewhat low \\
\hline Volition: & Okay because the lesson is short \\
\hline
\end{tabular}


The graph (Figure 3) clearly illustrates how there were combinations of positive and negative features on three of the components (A, R, and C).

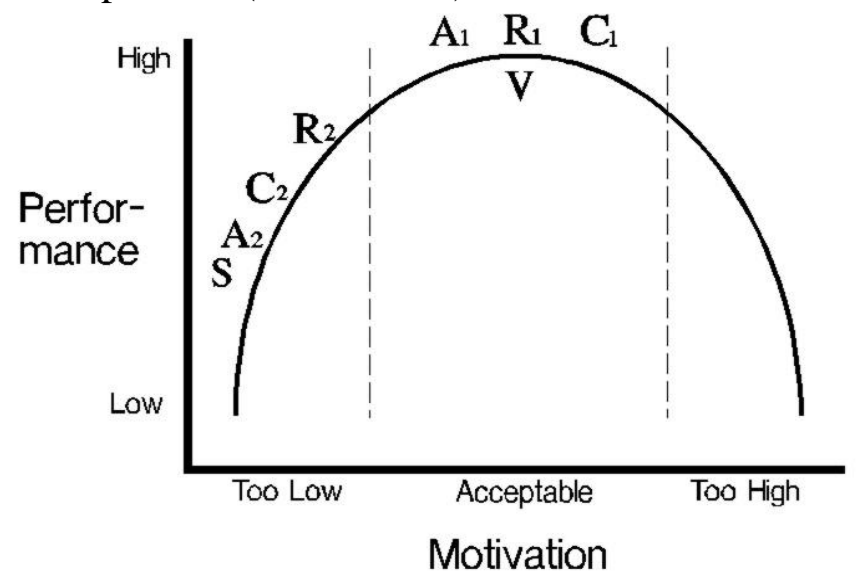

Figure 3. Motivational analysis results

\section{Motivational enhancements}

Based upon this analysis, the author made numerous revisions to this module of work. Following are the major changes:

1. Modified the "traditional" lesson plan with a "flipped classroom" approach that incorporated changes based on the results of the motivational analysis.

2. Expanded the homework requirements to read the assignment and participate in online discussion in which students checked their understanding and shared past experiences, if any, related to the topic. Participation was assessed.

3. Classroom activities spanned two weekly 3-hour sessions. Each session began with a brief lecture on critical success factors and real world examples from the instructor's field experiences and the experienced students' backgrounds.

4. Task analysis role play in class. The instructor chose the job of teacher which everyone would have experienced directly or indirectly. The instructor served as the analyst and interviewed the students to develop a listing of tasks comprising the job of teacher which we then organized into a task hierarchy.

5. Simulation in class of a job/task interview and data. The next step was for the students to play the role of analyst and conduct their analyses with two members of the class who had held a similar job before coming to the graduate program. This allowed the different groups to compare notes, discuss the differences between the two sets of data, which always happens in the real world, and to prepare a final job-task hierarchy.

6. Problem solving activity in class with actual corporate example. The instructor provided the results of an early stage of an analysis activity that he had conducted with a corporate client. The participants in the actual workshop had become "blocked;" that is, they became bogged down in their analysis effort. The students in the instructor's class worked in small groups to critique the draft analysis to see if they could identify the source of the blockage. This activity revealed the kinds of problems that actually occur when doing job-task analysis and allowed them to be prepared to deal with it in their application assignment and actual work experience.

7. Assignment: The final assignment in this module was for the students to do a real analysis and report it. The instructor guided them in the selection of suitable situations in which to conduct their analyses. 


\section{Motivational and performance results}

The student feedback on course evaluations indicated that all five motivational categories (ARCS-V) were satisfactory. There were increases in student interest in doing jobtask analysis and there were improvements in the quality of their final assignments. Also, they were able to do a job/task analysis without further instruction; that is, their skills transferred to other courses requiring a similar type of analysis and to their jobs when called upon to do so.

\section{eLearning version}

When the author began teaching an e-learning version of this class, the modifications to accommodate this different delivery system included some compromises compared to what could be done in the face-to-face environment, but it was possible to accomplish many of the same objectives. The students were still required to do background readings and discussion prior to the start of the module. Then, their first assignment was to work in teams of 2 or 3 to construct task hierarchies from given data. They did this in the small group feature of the online courseware. When finished, they posted their results to the class website and each team did a peer review of two other task hierarchies. The instructor provided a list of criteria to use for the critiques.

Following this learning activity, there was a group discussion of obstacles, issues, and hints pertaining to job/task analysis. The final step was to conduct and report the results of a job/task analysis in an actual work setting. There were other features, such as a group discussion board in which students could raise questions and concerns and both the instructor and other students could provide feedback. The performance results were not quite as strong as in the classroom setting, but were still effective and positive.

\section{Concluding statement}

There are huge challenges in managing the learning and motivational components of learning environments, especially with regard to integrating technology and innovative delivery systems. However, integrating the ARCS-V model with the ISD process can lead to instructionally rich and motivating learning events that are appropriate for a given setting. Analysis is key!

\section{Acknowledgement}

This paper is based on a keynote speech delivered at II. International Dynamic, Explorative and Active Learning (IDEAL) Conference, November 5-7, 2015, Amasya University, Amasya, Turkey

\section{References}

Bergmann, J. and A. Sams (2012). Flip your classroom: Reach every student in every class every day. New York, ISTE \& ASTD.

Bonk, C. J. and E. Khoo (2014). Adding some TEC-variety: 100+ activities for motivating and retaining learners online. Bloomington, Indiana, Open World Books.

Bonk, C. J. and K. Zhang (2008). Empowering online learning: 100+ Activities for reading, reflecting, displaying, \& doing. San Francisco, Jossey-Bass.

Deimann, M. and J. M. Keller (2006). "Volitional aspects of multimedia learning." Journal of Educational Multimedia and Hypermedia 15(2): 137-158.

Eitington, J. E. (2001). The winning trainer. New York, Routledge. 
Joyce, B. and M. Weil (1980). Models of Teaching. Englewood Cliffs, NJ, Prentice-Hall, Inc.

Keller, J. M. (1979). "Motivation and instructional design: A theoretical perspective." Journal of Instructional Development 2(4): 26 - 34.

Keller, J. M. (1983). Motivational design of instruction. Instructional design theories and models: An overview of their current status. C. M. Reigeluth. Hillsdale, NJ, Lawrence Erlbaum Associates.

Keller, J. M. (1984). The use of the ARCS model of motivation in teacher training. Aspects of Educational Technology Volume XVII: Staff Development and Career Updating. K. S. A. J. Trott. London, Kogan Page.

Keller, J. M. (1987). "Strategies for stimulating the motivation to learn." Performance \& Instruction 26(8): 1 - 7 .

Keller, J. M. (1987). "The systematic process of motivational design." Performance \& Instruction 26(9): 1 - 8.

Keller, J. M. (2008). "An integrative theory of motivation, volition, and performance." Technology, Instruction, Cognition, and Learning 6(2): 79-104.

Keller, J. M. (2010). Motivational design for learning and performance: The ARCS model approach. New York, Springer.

Kuhl, J. (1987). Action control: The maintenance of motivational states. Motivation, Intention and Volition. F. Halisch and J. Kuhl. Berlin, Springer: 279-291.

Suzuki, K. and J. M. Keller (1996). Creation and cultural validation of an ARCS motivational design matrix. Annual meeting of the Japanese Association for Educational Technology, Kanazawa, Japan.

Visser, L. (1998). The Development of Motivational Communication in Distance Education Support, Educational Technology Department, The University of Twente, The Netherlands.

Wheelwright, P. (1951). Aristotle. New York, The Odyssey Press.

Zimmerman, B. J. (2001). Theories of Self-Regulated Learning and Academic Achievement: An Overview and Analysis. Self-Regulated Learning and Academic Achievement. Theoretical Perspectives. B. J. Zimmerman and D. H. Schunk. Mahwah, N.J., Erlbaum: 1-38. 